\title{
PLANT-MEDIATED ZNO NANOPARTICLES USING FICUS RACEMOSA LEAF EXTRACT AND THEIR CHARACTERIZATION, ANTIBACTERIAL ACTIVITY
}

\author{
ARUN BABU BIRUSANTI ${ }^{1,2 *}$, UMAMAHESH MALLAVARAPU², DEVANNA NAYAKANTI ${ }^{1}$, \\ CHANDRA SEKHAR ESPENTI ${ }^{2}$
}

\begin{abstract}
${ }^{1}$ Department of Chemistry, JNTU College of Engineering and Technology, Anantapur, Andhra Pradesh, India. ${ }^{2}$ Department of Chemistry, Rajeev Gandhi Memorial College of Engineering and Technology, Nandyal, Kurnool, Andhra Pradesh, India. Email: birusanti.arunbabu@gmail.com
\end{abstract}

Received: 25 June 2018, Revised and Accepted: 02 August 2018

ABSTRACT

Objective: The motto of this research work was to synthesize the zinc oxide nanoparticles (ZnONPs) should be environmental friendly. Hence, it receives more attention toward the green route method.

Methods: At last, the Ficus racemosa ZnONPs (FR-ZnONPs) were successfully synthesized using a simple protocol and eco favorable technique. This paper highlights the biosynthesis of ZnONPs using leaf extract of F. racemosa.

Results: FR-ZnONPs formation was confirmed by the different spectral analysis such as UV-visible spectroscopy, Fourier transform-infrared spectroscopy (FTIR), X-ray diffraction (XRD), transmission electron microscopy (TEM), and electronic dispersive X-ray spectroscopy. UV-visible studies revealed that the intrinsic band gap absorptions were at $372 \mathrm{~nm}$ and photoluminescence study showed that the blue emission at 492 , 481, 473 , and $450 \mathrm{~nm}$ and the green emission at $540 \mathrm{~nm}$, respectively. FR-ZnONPs are wurtzite hexagonal structure with an average grain size of $15 \mathrm{~nm}$ was found from XRD analysis.

Conclusion: FR-ZnONPs exhibited good antimicrobial efficacy on Escherichia coli and Staphylococcus aureus with various concentrations (100 $\mu$ g/mL, $75 \mu \mathrm{g} / \mathrm{mL}$, and $50 \mu \mathrm{g} / \mathrm{mL}$ ) by disc diffusion method. The results showed the good antibacterial activity of FR-ZnONPs on $\mathrm{G}^{\text {+ve }}$ and $\mathrm{G}^{\text {-ve }}$ bacteria.

Key words: Green synthesis, Ficus racemosa, Ficus racemosa - zinc oxide nanoparticles, Transmission electron microscopy, Antibacterial activity.

(C) 2018 The Authors. Published by Innovare Academic Sciences Pvt Ltd. This is an open access article under the CC BY license (http://creativecommons. org/licenses/by/4. 0/) DOI: http://dx.doi.org/10.22159/ajpcr.2018.v11i9.28084

\section{INTRODUCTION}

The development of nanotechnology has made a revolutionary impact on each stage of human life. The coalescence of nanotechnology with green chemistry is creating an exciting horizon to synthesize immaculate and green multifunctional nanoparticles (NPs). Multifunctional NPs are symphonized globally, due to their various significant and magnificent properties, to facilitate their exploitation in various research areas such as nanomedicine, nanodiagnostics, nanoemulsions, nanosomes, and delivery vehicles [1-3]. Among the various metal oxide NPs, zinc oxide $(\mathrm{ZnO})$ is interesting because it is inexpensive to produce, and authentically USFDA has enlisted $\mathrm{ZnO}$ as generally recognized as safe [2]. $\mathrm{ZnO}$ is perpetuating its vast applications in various areas such as gene therapy and drug delivery due to their large surface area, versatile phototoxic effect and in surface chemistry, etc. ZnONPs exhibit significant optical, piezoelectric, magnetic, and gas sensing applications [3-5]. ZnONPs are also playing an important role in strong adsorption ability, high catalytic efficiency and are utilized frequently in the fabrication of skin protection materials, rubber processing, ceramics, and wastewater treatment processes [6,7]. ZnO nanocrystals possess large second and third order nonlinearities and generate the second-harmonic and sum-frequency generations and in electronic four-wave mixing effectively connects to living microscopic species [8]. A much effort has been devoted for the development of less toxic fluorescent ZnONPs and nanocomposites [9].

Biosynthesis of NPs is an approach of fabricating NPs utilizing plants finds biomedical applications such as antibacterial activity. The researchers are now mainly focusing on biosynthesis of metal NPs (MNPs) utilizing plant extracts due to its sustainable, quick, nontoxic, eco-friendly, low cost, eco favorable, and green approach stage for preparing ZnONPs [10]. The interfaces of therapeutic plants and biogenic metal nanoparticles for designing nanomaterials with assorted applications [11]. Medicinal plants are generally favored to utilize them for the synthesis of NPs due to rich photosensitive and bioactive compounds [12]. The conventional methods and chemical technologies operate less time for the synthesis of large quantities of NPs, but they require harmful chemicals as capping agents to maintain stability, and this line leads to more toxicity into the environment [13]. To overcome this problem, researchers interest has turned in the direction of green synthesis of NPs. MNPs synthesis involves three steps on green synthesis aspect: (i) Selection of solvent medium, (ii) reducing agents, and (iii) stabilizing agents should be environmentally friendly and non-toxic $[14,15]$. Plant species Lamiaceae family such as Plectranthus amboinicus [16], Anisochilus carnosus [17], and Vitex negundo [18] have been reported for NPs production of different sizes and shapes such as circular, semi-round, hexagonal, and bar form with agglomeration. The results clearly indicated that the formation of the size of NPs decreases with increasing concentration of plant extract [16-18]. ZnONPs fabricated by the green route method by utilizing plant extracts of Calotropis procera and Aloe vera [19,20]. Ficus racemosa (FR) is commonly known as gular and has been used extensively in the treatment of biliary disorders, jaundice, dysentery, diarrhea, etc. [21]. The authors for the $1^{\text {st }}$ time prepared ZnONPs using leaf extract of FR due to its many applications. The formation of FR-ZnONPs was confirmed by different spectral characterizations.

\section{MATERIALS AND METHODS}

Preparation of leaf extract

Leaves of FR plant were collected during early sunshine hours from Nallamalla dense forests, Eastern Ghats, India. The leaves were 
thoroughly washed with flowing stream water and subsequently with distilled water for several times to remove any dust particles and permitted to air dry at room temperature. Dry leaves were cut into fine pieces, weighed $10 \mathrm{~g}$, and transferred into $250 \mathrm{~mL}$ round bottom flask containing $100 \mathrm{~mL}$ distilled water, mixed well, and boiled at $60-80^{\circ} \mathrm{C}$ for 30 min on magnetic stirrer. Aqueous leaf extract converted into light yellowish color and filtered this solution using Whatman filter paper at room temperature. The plant extract was stored in the refrigerator at $4^{\circ} \mathrm{C}$ and utilized for the preparation of ZnONPs.

\section{Preparation of FR-ZnONPs}

Zinc nitrate hexahydrate $\left(\mathrm{Zn}\left(\mathrm{NO}_{3}\right)_{2} \bullet 6 \mathrm{H}_{2} \mathrm{O}\right)$ purchased from the Sigma-Aldrich Chemicals Pvt. Ltd., Hyderabad, Telangana, India. It was employed in the present study and the solution was prepared as reported in the literature [22]. The present study synthesis $2.5 \mathrm{~mL}$ of $0.01 \mathrm{M}$ of zinc nitrate solution was added to the different amounts $(15,25$, and $35 \mathrm{~mL})$ of $10 \%$ FR extract which is allowed to boil under constant stirring with magnetic stirrer at room temperature. After complete dissolution of the mixture, the solution was kept under vigorous stirring at $80^{\circ} \mathrm{C}$ for $2 \mathrm{~h}$, and the product was allowed to cool at room temperature. The light brown product obtained was centrifuged at 10,000 rpm for $15 \mathrm{~min}$ and transferred into the Petri dishes and dried in hot air oven at $75^{\circ} \mathrm{C}$ for $8 \mathrm{~h}$. The obtained product was transferred into the ceramic crucible cup and heated in a furnace at $400^{\circ} \mathrm{C}$ for $2 \mathrm{~h}$. A light brown colored powder of FR-ZnONPs was obtained and used for the further study.

$$
\begin{aligned}
& \mathrm{Zn}\left(\mathrm{NO}_{3}\right)_{2} \cdot 6 \mathrm{H}_{2} \mathrm{O}+\begin{array}{l}
\text { Ficus racemosa } \\
\text { aqueous leaf extarct }
\end{array} \stackrel{\triangle}{\text { Stirring }} \mathrm{Zn}-(\mathrm{OH})_{2}-2 \mathrm{NO}_{3} \\
& \mathrm{Zn}-(\mathrm{OH})_{2}-2 \mathrm{NO}_{3} \underset{\text { At } 400{ }^{\circ} \mathrm{C}}{\stackrel{\text { Sintering }}{\longrightarrow}} \mathrm{ZnONPs}+2 \mathrm{NO}_{3} \uparrow+\mathrm{H}_{2} \mathrm{O} \uparrow
\end{aligned}
$$

\section{Characterization of FR-ZnONPs}

FR-ZnONPs were characterized by the IR spectra were recorded on a Perkin-Elmer 283 unit. Initial confirmation for the formation of FRZnONPs was tested by UV-visible spectrophotometer (Shimadzu-1240, Tokyo, Japan), photoluminescence (PL) study was executed by the FLS980 spectrometer using $450 \mathrm{~W}$ ozone free xenon arc lamp with excitation wavelength at $372 \mathrm{~nm}$. TGA was studied on SHIMADZU DTG$60 \mathrm{H}$ at a heating rate of $10^{\circ} \mathrm{C} / \mathrm{min}$ under dry nitrogen atmosphere. X-ray diffraction (XRD) analysis was carried out for FR-ZnONPs with PANalytical X'PERT PRO model XRD operated at $30 \mathrm{kv} 45 \mathrm{~mA}$ with $\mathrm{Cu}$ $\mathrm{X}$-ray tube as a radiation source to record the crystalline nature of the FR-ZnONPs, and the crystalline size was calculated using the Scherrer equation. Transmission electron microscopy (TEM) measurements were carried out on JEOL model 1200 EX instrument on copper grids with an accelerating voltage of $80 \mathrm{kV}$.

\section{RESULTS AND DISCUSSION}

UV-visible spectral analysis

The UV-visible spectrum recorded at three different concentrations for the preliminary confirmation of FR-ZnONPs was given in Fig. 1. The SPR band at $372 \mathrm{~nm}$ as shown in Fig. 1 corresponds to the intrinsic band gap absorption of FR-ZnONPs. Due to the electron transitions from valence band to the conduction band. These results are in accordance with the earlier reports [23]

\section{Fourier transform-infrared (FTIR) analysis}

To study the chemical interaction between FR, ZnONPs, and formation of FR-ZnONPs, the FTIR spectra were recorded and are presented in Fig. 2. The plant extract plays a dual role as a reducing and capping agent, their presence was confirmed by FTIR investigation. FR leaves contain different biomolecules such as catechins, pelargonin, kaempferol, rutin, arabinose, bergapten, psoralenes, ficusin, leucopelargonin, high molecular tannins, and flavonoids. The broad characteristic peak at $3436.07 \mathrm{~cm}^{-1}$ represents the $\mathrm{N}-\mathrm{H}$ stretching vibration of amino groups. The characteristic peaks at $3850.76 \mathrm{~cm}^{-1}$ and $3746.41 \mathrm{~cm}^{-1}$ represent

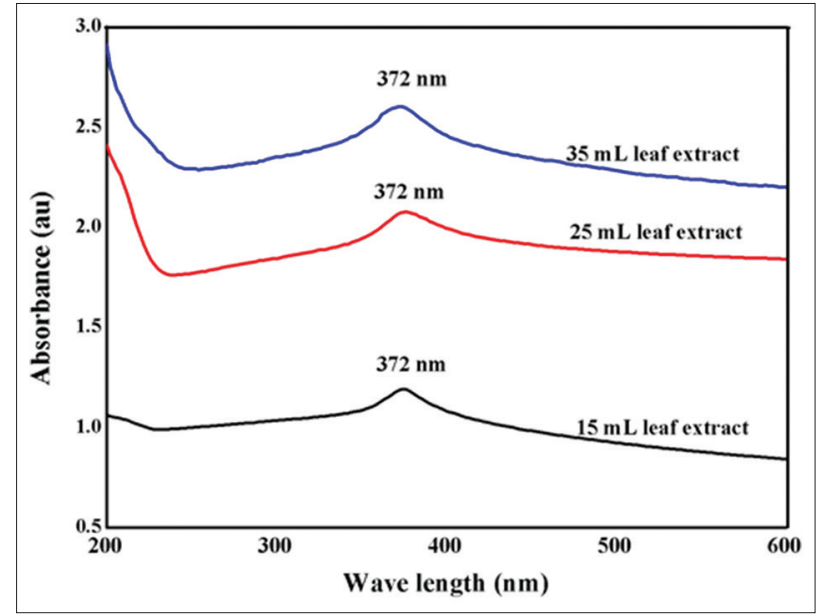

Fig. 1: Ultraviolet-visible spectra of Ficus racemosa zinc oxide nanoparticles

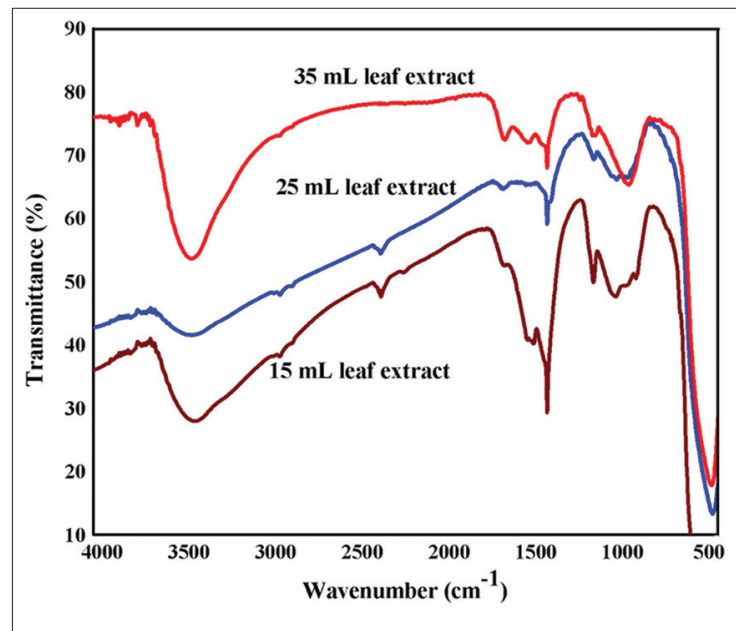

Fig. 2: Fourier transform infrared spectra of Ficus racemosa zinc oxide nanoparticles

the presence of free-OH groups of the phenolic compounds of the leaf extract. The strong band at $1627.21 \mathrm{~cm}^{-1}$ corresponds to stretching vibrations of $\mathrm{C}=0$ functional groups and at $1384.48 \mathrm{~cm}^{-1}$ refers to the amine - $\mathrm{NH}$ vibration stretch in amide linkages. On the other hand, the extract sample prepared shows a wide and strong peak with maximum intensity at $553 \mathrm{~cm}^{-1}$ which corresponds to the alkyl halides present in the obtained product. The results are in good agreement with those found in literature $[24,25]$.

\section{XRD analysis}

XRD is taken to further confirm of FR-ZnONPs. Crystal lattice indices and particle size calculations were performed using the XRD pattern of FR-ZnONPs (Fig. 3). XRD diffraction peaks of FR-ZnONPs were observed at $31.78^{\circ}, 34.33^{\circ}, 36.22^{\circ}, 47.50^{\circ}, 56.57^{\circ}, 62.88^{\circ}, 66.31^{\circ}, 68.03^{\circ}, 69.04^{\circ}$, $72.03^{\circ}$, and $76.48^{\circ}$ and were assigned to $\left(\begin{array}{lll}1 & 0 & 0\end{array}\right),\left(\begin{array}{lll}0 & 0 & 2\end{array}\right),\left(\begin{array}{lll}1 & 0 & 1\end{array}\right)$, ( (1 $\left.\begin{array}{ll}0 & 2\end{array}\right),\left(\begin{array}{lll}1 & 1 & 0\end{array}\right),\left(\begin{array}{lll}1 & 0 & 3\end{array}\right),\left(\begin{array}{lll}2 & 0 & 0\end{array}\right),\left(\begin{array}{lll}1 & 1 & 2\end{array}\right),\left(\begin{array}{lll}2 & 0 & 1\end{array}\right),\left(\begin{array}{lll}0 & 0 & 4\end{array}\right)$, and $\left(\begin{array}{lll}2 & 0 & 2\end{array}\right)$ crystal planes of the hexagonal wurtzite structure of the FR-ZnONPs. Before calcination, two unwanted peaks were identified at $18.75^{\circ}$ and $32.95^{\circ}$ may be related to organic moieties involved in the process of preparation of FR-ZnONPs [26]. From the X-ray diffractogram confirms the pure and well crystalline nature of the FR-ZnONPs with strong intensity and narrow width of peaks. The crystalline size of the FRZnONPs was also calculated with the help of strong intensity peak using Debye-Scherrer's equation [27]. 


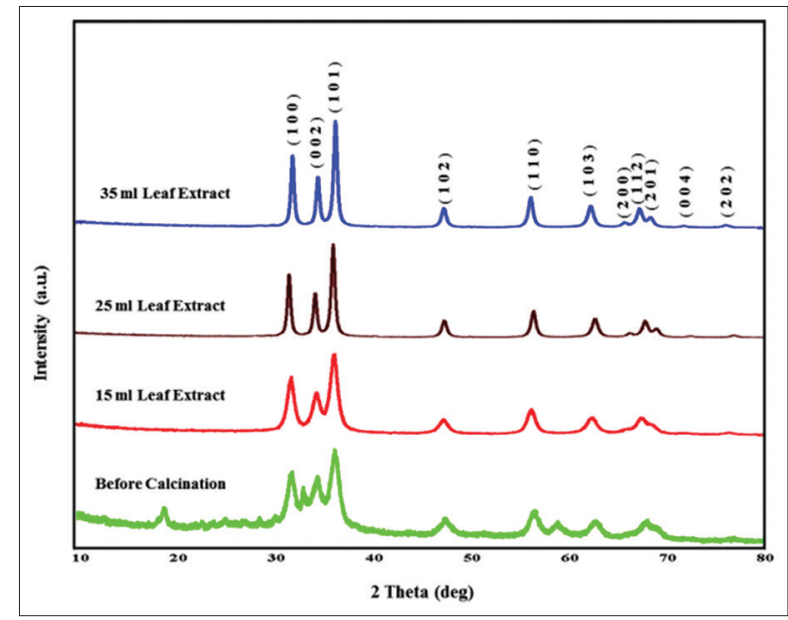

Fig. 3: X-ray diffraction spectrum of Ficus racemosa zinc oxide nanoparticles before calcination ( $35 \mathrm{~mL}$ leaf extract) and after calcination (15 mL leaf extract, $25 \mathrm{~mL}$ leaf extract, and $35 \mathrm{~mL}$ leaf extract)

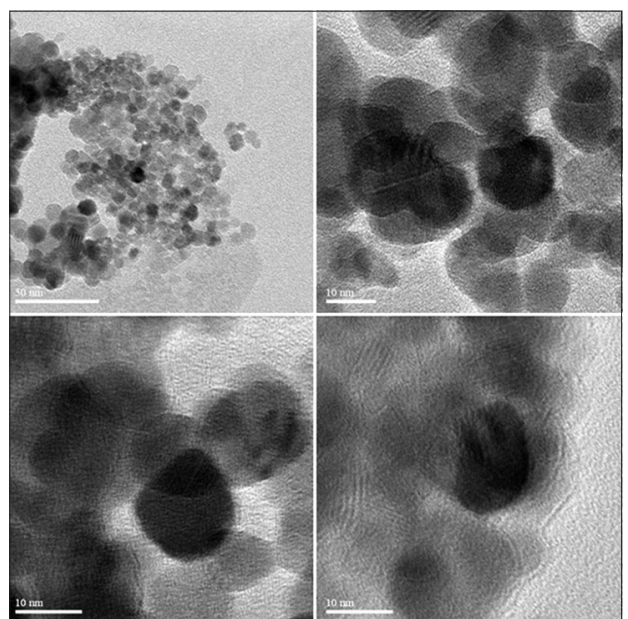

Fig. 4: Transmission electron microscopic photographs of Ficus racemosa leaves extract mediated $\boldsymbol{F}$ racemosa zinc oxide nanoparticles at different magnifications

$\mathrm{D}=\frac{0.89 \lambda}{\beta \cos \theta}$

Where, $0.89=$ Scherrer's constant,

$\mathrm{D}=$ Average crystal size

$\lambda=$ Wavelength of the X-ray radiation $(\mathrm{Cu} \mathrm{K \alpha})$

$\beta=$ Full width at half-maximum of the FR-ZnONPs of $\left(\begin{array}{lll}1 & 0 & 1\end{array}\right)$ line.

$\theta=$ Bragg's angle of diffraction

The calculated average crystalline size from the high intense plane of (101) was $14.8 \mathrm{~nm}$.

\section{TEM analysis}

The confirmation of the nanostructure morphology and size of FRZnONPs comes from the analysis of TEM micrographs (Fig. 4). These images revealed that the FR-ZnONPs were quasi-spherical and their size was around $\sim 15 \mathrm{~nm}$. The particle size estimated from the TEM micrographs is in good agreement with that of the XRD analysis.

\section{Electronic dispersive X-ray (EDX) analysis}

EDX technique was carried out to determine the chemical composition of the sample. Fig. 5 showed that the EDX spectrum of FR-ZnONPs

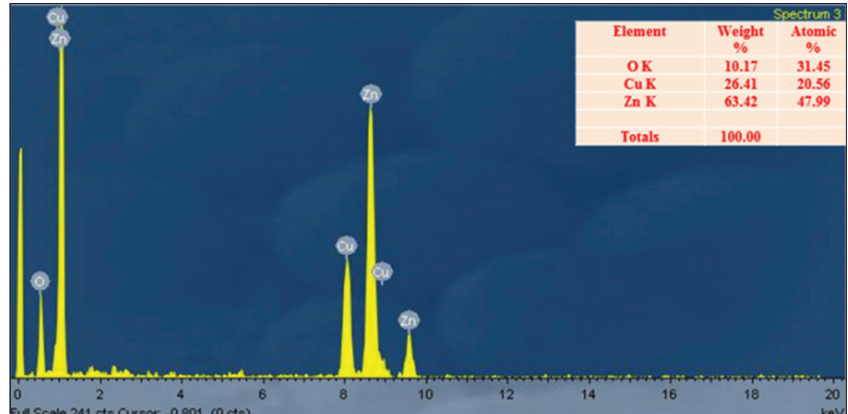

Fig. 5: Electronic dispersive X-ray spectrum of Ficus racemosa zinc oxide nanoparticles

prepared by the aqueous solution method. The strong peaks observed from spectrum related to zinc and oxygen. The elemental constituents of FR-ZnONPs with two concern peaks were found to have a weight percentage of $63.42 \%$ of zinc and $\mathrm{O}_{2}-10.17 \%$. The EDX technique enables atomic species analysis locally in the synthesized sample and this confirmed choosing the aqueous solution method process of ZnONPs are environmentally benign.

\section{PL analysis}

PL spectral studies were also studied at room temperature to confirm the formation of FR-ZnONPs and are presented in Fig. 6. Three samples with different concentrations $(15,25$, and $35 \mathrm{~mL}$ of leaf extracts) exhibited similar emission and excitation spectra. The emission in UV area is credited to the recombination between electrons in the conduction band and openings in the valence band. PL spectrum of FRZnONPs showed several emission bands of blue $(492,481,473,462$, and $450 \mathrm{~nm}$ ) concern with the defect structure of the FR-ZnONPs and green emission band at $540 \mathrm{~nm}$ is ascribed to the presence of independent ionized oxygen vacancies. This emission is due to the radiative recombination of photogenerated gap with an electron involving in the oxygen opening [28].

\section{TG-DTA analysis}

Thermal behavior of FR-ZnONPs was tested by TG-DTA and is represented in Fig. 7. The sample was heated in the aluminum pan from $0^{\circ} \mathrm{C}$ to $1000^{\circ} \mathrm{C}$ at a heating rate of $10^{\circ} \mathrm{C} / \mathrm{min}$. From the Fig. $7 \mathrm{a}$, continuous weight loss occurred from $27.39^{\circ} \mathrm{C}$ to $1000^{\circ} \mathrm{C}$, major weight loss happened between $510^{\circ} \mathrm{C}$ and $850^{\circ} \mathrm{C}$, due to the decomposition of organic moieties present in the sample [29] and conversion of FR$\mathrm{ZnONPs}$ to $\mathrm{Zn}$ and oxygen [30]. The total weight loss of the sample was around $6.975 \%$. The DTA curve in Fig. 7 shows three exothermic peaks at $53.89^{\circ} \mathrm{C}, 81.75^{\circ} \mathrm{C}$, and $272.24^{\circ} \mathrm{C}$ indicates the removal of water and decomposition of organic components.

\section{Antibacterial activity of FR-ZnONPs}

FR-ZnONPs were screened for their antibacterial activity against $\mathrm{G}^{\text {+ve }}$ bacteria such as Staphylococcus aureus and $\mathrm{G}^{\text {-ve }}$ bacteria such as Escherichia coli by the disc diffusion method [23] in nutrient agar medium at three different concentrations $(50 \mu \mathrm{g} / \mathrm{mL}, 75 \mu \mathrm{g} / \mathrm{mL}$, and $100 \mu \mathrm{g} / \mathrm{mL}$ ) of FR-ZnONPs in millipore water. Fresh overnight cultures were taken and spread on the nutrient agar plates to cultivate bacteria on sterile paper discs of $6 \mathrm{~mm}$ diameter saturated with FR-ZnONPs were placed on each plate and incubated at $37^{\circ} \mathrm{C}$ for $24 \mathrm{~h}$, and the antibacterial activity was estimated in view of the resistance zone around the disc impregnated with synthesized FR-ZnONPs in Fig. 8 [31]. The zone of inhibition exhibited by FR-ZnONPs against two bacterial strains was also compared with the activity of the standard antibiotic gentamycin in Table 1. The entire tests were done in triplicates.

\section{CONCLUSION}

The present study illustrates the fabrication of FR-ZnONPs using the leaf extract of FR in an environmentally benign and eco-friendly method. 


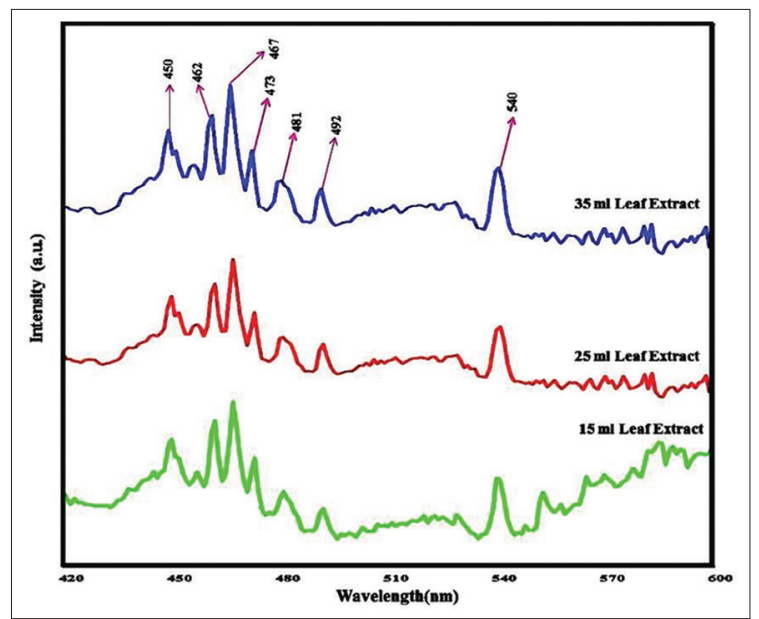

Fig. 6: Photoluminescence spectra of Ficus racemosa zinc oxide nanoparticles at room temperature

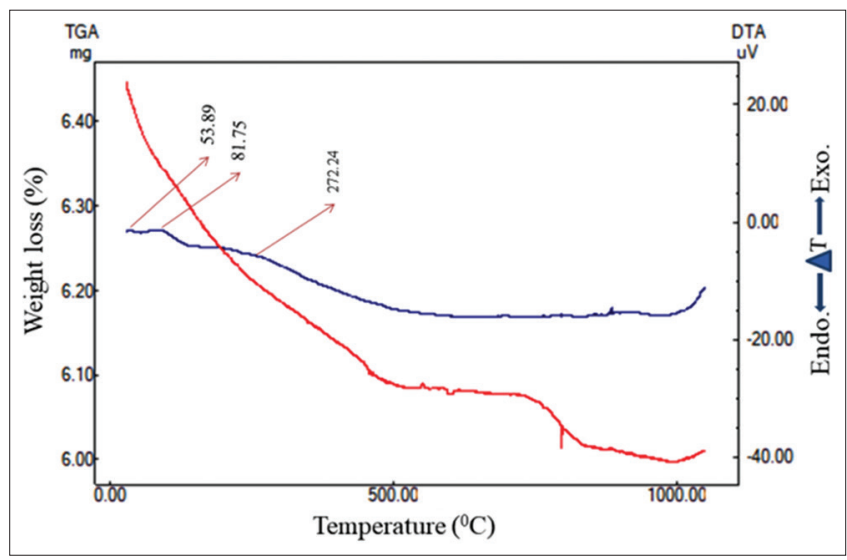

Fig. 7: Thermograph of Ficus racemosa zinc oxide nanoparticles

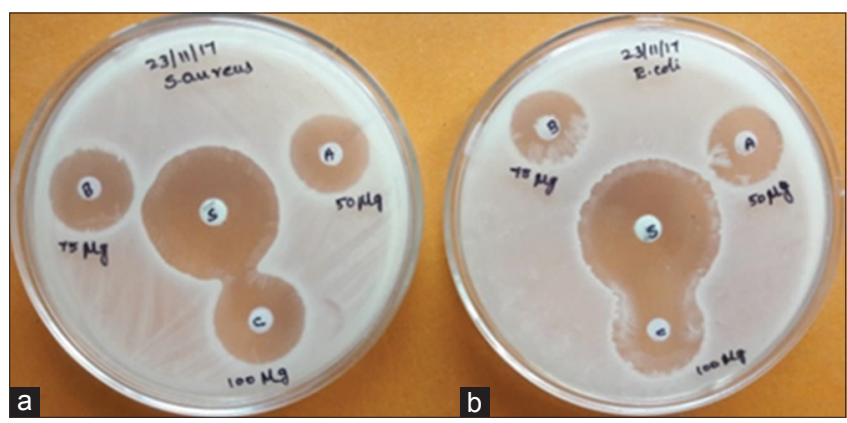

Fig. 8: Screening of antibacterial activity of prepared Ficus racemosa- zinc oxide nanoparticles against (a) Staphylococcus aureus, (b) Escherichia coli

Table 1: Antibacterial activity of prepared FR-ZnONPs by FR leaf extract

\begin{tabular}{lllll}
\hline \multirow{2}{*}{$\begin{array}{l}\text { Tested } \\
\text { pathogens }\end{array}$} & \multicolumn{4}{l}{ Zone of inhibition (mm) } \\
\cline { 2 - 5 } & $\mathbf{5 0} \boldsymbol{\mu g} / \mathbf{m L}$ & $\mathbf{7 5} \boldsymbol{\mu g} / \mathbf{m L}$ & $\mathbf{1 0 0} \boldsymbol{\mu g} / \mathbf{m L}$ & Gentamycin \\
\hline S. aureus & $19 \pm 0.56$ & $21 \pm 1.64$ & $23 \pm 1.00$ & 33 \\
E. coli & $18 \pm 0.66$ & $19 \pm 0.84$ & $23 \pm 1.16$ & 34 \\
\hline
\end{tabular}

E. coli: Escherichia coli, S. aureus: Staphylococcus aureus, ZnONPs: Ficus racemosa zinc oxide nanoparticles, FR: Ficus racemosa
UV-visible analysis showed a significant sharp SRP peak at $372 \mathrm{~nm}$, and it was the primary confirmation of the formation of FR-ZnONPs. The FTIR analysis revealed the possible functional groups present in the FR leaf extract and involvement of organo bioactive components in the bioreduction of $\mathrm{Zn}\left(\mathrm{NO}_{3}\right)_{2}$ to form the ZnONPs. The XRD study reveals the wurtzite hexagonal structure and size of the FR-ZnONPs was around $14.8 \mathrm{~nm}$, and it is almost equal to the TEM measurements. Elemental analysis was carried out by EDX, and it gives the weight \% and atomic $\%$ of the elements present in the FR-ZnONPs. Thermal behavior of the FR-ZnONPs was analyzed by the TG-DTA. It also exhibited antibacterial activity against $\mathrm{G}^{\text {+ve }}$ and $\mathrm{G}^{-\mathrm{ve}}$ bacteria.

\section{ACKNOWLEDGMENTS}

The authors expressed their thanks to the Chairman and principal for providing necessary research facilities in the department of Chemistry, RGMCET, Nandyal. The authors acknowledge MoU-DAE-BRNS project (No.2009/34/36/BRNS/3174), Department of Physics, S.V.University, Tirupati, India for providing the experimental facility.

\section{AUTHOR'S CONTRIBUTIONS}

ABB designed the study, the main conceptual ideas, and performed the experiment. UM and DN worked out in technical details and performed numerical calculations. CSE helped in the throughout writing in the manuscript.

\section{CONFLICTS OF INTEREST}

The authors declare that they have no conflicts of interest.

\section{REFERENCES}

1. Sastry M, Ahmad A, Khan MI, Kumar R. Biosynthesis of metal nanoparticles using fungi and actinomycete. Curr Sci 2003;85:162-70.

2. Pulit-prociak J, Chwastowski J, Kucharski A, Banach M. Applied surface science functionalization of textiles with silver and zinc oxide nanoparticles. Appl Surf Sci 2016;385:543-53.

3. Patel P, Kansara K, Senapati VA, Shenkar R, Dhawan A, Kumar A. Cell cycle dependent cellular uptake of zinc oxide nanoparticles in human epidermal cells. Mutagenesis 2016;31:481-90.

4. Nagajyothi PC, Sreekanth TV, Tettey CO, Jun YI, Mook SH. Characterization, antibacterial, antioxidant, and cytotoxic activities of $\mathrm{ZnO}$ nanoparticles using coptidis rhizoma. Bioorg Med Chem Lett 2014;24:4298-303.

5. Kumar SR. Synthesis of silver nanoparticles using fresh bark of Pongamia pinnata and characterization of its antibacterial activity against gram positive and gram negative pathogens. Resour Technol 2016;2:30-5

6. LiQ, Mahendra S, Lyon DY, Brunet L, Liga MV, Li D, et al. Antimicrobial nanomaterials for water disinfection and microbial control: Potential applications and implications. Water Res 2008;42:4591-602.

7. Wodka D, Bielaníska E, Socha RP, Wodka ME, Gurgel J, Nowak P, et al. Photocatalytic activity of titanium dioxide modified by silver nanoparticles. ACS Appl Mater Interfaces 2010;2:1945-53.

8. Kumar BA. ZnO Nanoparticles: Recent biomedical applications and interaction with proteins. Curr Trends Biomed Eng Biosci 2017;6:1-4.

9. Bhunia AK, Jha PK, Rout D, Saha S. Morphological properties and raman spectroscopy of ZnO nanorods. J Phys Sci 2016;21:111-8.

10. Kavitha S, Dhamodaran M, Prasad R, Ganesan M. Synthesis and characterisation of zinc oxide nanoparticles using terpenoid fractions of Andrographis paniculata leaves. Int Nano Lett 2017;7:141-7.

11. Kitching M, Ramani M, Marsili E. Fungal biosynthesis of gold nanoparticles: Mechanism and scale up. Microb Biotechnol 2015;8:904 17.

12. Das C, Debta P, Das D, Ghosh G. Cytomorphological and physicochemical studies of sida rhombifolia. Int $\mathrm{J}$ Pharm Pharm Sci 2018:7:46 -56

13. Sabir S, Arshad M, Chaudhari SK. Zinc oxide nanoparticles for revolutionizing agriculture: Synthesis and applications. Sci World J 2014;Article ID 925494:1-8.

14. Yu J, Xu D, Guan HN, Wang C, Huang LK, Chi DF. Facile one-step 
green synthesis of gold nanoparticles using Citrus maxima aqueous extracts and its catalytic activity. Mater Lett 2016;166:110-2.

15. Mata R, Bhaskaran A, Sadras SR. Green-synthesized gold nanoparticles from Plumeria alba flower extract to augment catalytic degradation of organic dyes and inhibit bacterial growth. Particuology 2016;24:78-86.

16. Fu L, Fu Z. Plectranthus amboinicus leaf extract-assisted biosynthesis of $\mathrm{ZnO}$ nanoparticles and their photocatalytic activity. Ceram Int 2015;41:2492-6.

17. Anbuvannan M, Ramesh M, Viruthagiri G, Shanmugam N, Kannadasan N. Anisochilus carnosus leaf extract mediated synthesis of zinc oxide nanoparticles for antibacterial and photocatalytic activities. Mater Sci Semicond Process 2015;39:621-8.

18. Ambika S, Sundrarajan M. Antibacterial behaviour of Vitex negundo extract assisted $\mathrm{ZnO}$ nanoparticles against pathogenic bacteria. J Photochem Photobiol B 2015;146:52-7.

19. Singh RP, Shukla VK, Yadav RS, Sharma PK, Singh PK, Pandey AC. Biological approach of zinc oxide nanoparticles formation and its characterization. Adv Mater Lett 2011;2:313-7.

20. Sangeetha G, Rajeshwari S, Venkatesh R. Green synthesis of zinc oxide nano particles by Aloe barbadensis miller leaf extract: Structure and optical properties. Mater Res Bull 2011;46:2560-6.

21. Ahmed F, Urooj A. Traditional uses, medicinal properties, and phytopharmacology of ficus racemosa: A review. J Pharm Biol 2010;48:672-81.

22. Suresh D, Udayabhanu, Nethravathi PC, Lingaraju K, Rajanaika H, Sharma SC, et al. EGCG assisted green synthesis of znO nanopowders: Photodegradative, antimicrobial and antioxidant activities. Spectrochim Acta A Mol Biomol Spectrosc 2015;136 Pt C:1467-74.

23. Cruickshank R. Medicinal Microbiology, a Guide to Diagnosis and
Control of Reaction. $11^{\text {th }}$ ed. Edinburgh and London, U. K: E. and S Livingstone; 1975. Available from: https://www.trove.nla.gov.au/ version $/ 45379343$

24. Suresh D, Shobharani RM, Nethravathi PC, Kumar MA, Nagabhushana H, Sharma SC. Artocarpus gomezianus aided green synthesis of $\mathrm{ZnO}$ nanoparticles: Luminescence, photocatalytic and antioxidant properties. Spectrochim Acta A Mol Biomol Spectrosc 2015;141:128-34.

25. Jamdagni P, Kharti P, Rana JS. Green synthesis of zinc oxide nanoparticles using flower extract of Nyctanthes arbor-tristis and their antifungal activity. J King Saud Univ Sci Press 2018;2:168-75.

26. Silverstein RM, Webster FX, Kiemle DJ. Spectrometric Identification of Organic Compounds. $6^{\text {th }}$ ed. New York: Wiley; 1998.

27. Selvaraj MR, Madhumitha GR, Abdul AR, Kamaraj C, Bharathi A, Surendra TV, et al. Low-cost and eco-friendly phyto-synthesis of silver nano particles using Cocos nucifera coir extract and its larvicidal activity. Ind Crops Prod 2013;43:631-5.

28. Talam S, Karumuri SR, Gunnam N. Synthesis, characterization, and spectroscopic properties of $\mathrm{ZnO}$ nanoparticles. ISRN Nanotechnol 2012;2012:372505.

29. Zhou J, Zhao F, Wang Y, Zhang Y, Yang L. Size controlled synthesis of $\mathrm{ZnO}$ nanoparticles and their photoluminescence properties. J Lumin 2007; 122-123:195-7.

30. Khalil MI, Al-qunaibit MM, Al-zahem AM, Labis JP. Synthesis and Characterisation of $\mathrm{ZnO}$ nanoparticles by thermal decomposition of a curcumin zinc complex. Arab J Chem 2014;7:1178-84.

31. Moharram BA, Al-Mahbashi HM, Saif-Ali R, AliAqlan F. Phytochemical, anti-inflammatory, antioxidant, cytotoxic and antibacterial study of capparis cartilaginea decne fromyemen. Int J Pharm Pharm Sci 2018;10:38-4. 